\title{
Evaluating the rate of migration of an uranium deposition front within the Uitenhage Aquifer
}

\author{
J.C. Vogel ${ }^{\text {a }}$, A.S. Talma ${ }^{\text {a }}$, T.H.E. Heaton ${ }^{\text {b }}$, J. Kronfeld ${ }^{\text {c,* }}$ \\ ${ }^{a}$ Quaternary Dating Research Unit, Environmentek, C.S.I.R., P.O. Box 395, Pretoria 0001, South Africa \\ ${ }^{b}$ NERC Isotope Geosciences Laboratory, Keyworth, Nottingham, UK \\ ${ }^{c}$ Department of Geophysics and Planetary Science, Raymond and Beverly Sackler Faculty of Exact Science, Tel-Aviv University, \\ Tel-Aviv, Israel
}

\begin{abstract}
The solubility of uranium in groundwater is very sensitive to changes in redox conditions. Many secondary (sandstonetype) uranium deposits have been formed when soluble $U$ has precipitated after encountering reducing conditions in the subsurface. In the groundwater of the Uitenhage Aquifer (Cape Province, South Africa), ${ }^{238} \mathrm{U}$-series isotopes were used to assist in studying the history of the reducing barrier. Uranium isotopes were used to determine the present position of the barrier. Radium and radon were used to evaluate the path of migration that the front of the oxygen depletion zone has taken over the past $10^{5}$ years. During this time the reducing barrier has moved, leaving in its wake a trail of $\mathrm{U}$ in various stages of secular equilibrium with its daughter ${ }^{230} \mathrm{Th}$. The ${ }^{226} \mathrm{Ra}$ daughter of ${ }^{230} \mathrm{Th}$ is not very mobile. Its growth upon the aquifer wall is reflected in the Rn content of the water. This in turn, due to the relatively great age of the water, indicates the extent of the ${ }^{230} \mathrm{Th}$ ingrowth (from precipitated U) that took place before the barrier migrated. (C) 1999 Elsevier Science B.V. All rights reserved.
\end{abstract}

Keywords: uranium series; sandstone-type uranium deposit; redox changes in aquifer; South Africa

\section{Introduction}

Uranium in groundwater is soluble under oxidizing conditions. When oxygen depletion is encountered (at a reducing barrier), $\mathrm{U}$ precipitates as the soluble $\mathrm{U}^{6+}$ is reduced to the insoluble $\mathrm{U}^{4+}$ valence state. The position of the reducing barrier in an active aquifer is of geochemical interest to the prospecting geologist as well as to the hydrologist, who employs ${ }^{234} \mathrm{U} /{ }^{238} \mathrm{U}$ as a natural groundwater tracer. Under the right conditions, this site can develop into a zone of

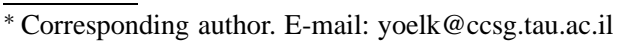

U-ore accumulation. Moreover, water flowing past this redox change may have its U-isotopic signature drastically altered. At the barrier, the concentration of $U$ will become greatly reduced as the element precipitates. Coupled to this will be a significant rise in the ${ }^{234} \mathrm{U} /{ }^{238} \mathrm{U}$ activity ratio as the ${ }^{234} \mathrm{U}$ isotope selectively is injected from the accumulating $U$ source into the water by alpha-recoil processes (Kigoshi, 1971; Kronfeld, 1974).

Though reducing zones have been often encountered during hydrological studies, very little direct information has been obtained regarding the age of the barrier, its stability, or the direction of movement 


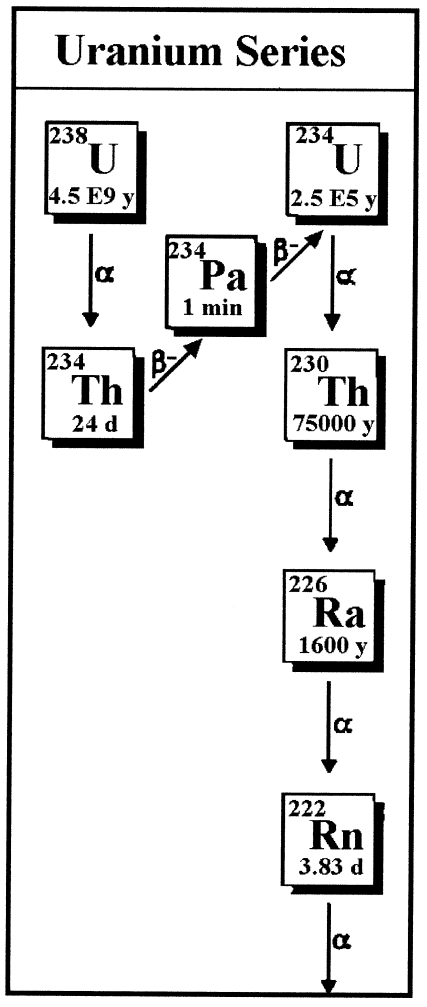

Fig. 1. Uranium decay series (through radon), with the relevant half-lives of the isotopes.

that it may have taken. During the course of an investigation of the Uitenhage Aquifer, a reducing barrier was encountered. Uranium, radium, and radon of the ${ }^{238} \mathrm{U}$-series were employed to study the movement of the reducing barrier over time. The relevant portion of the decay series, along with the half-lives of the isotopes is presented in Fig. 1. The Th isotopes were not measured directly, since Th under the chemical conditions of the aquifer is too insoluble to be detected. The carbonate solution chemistry, age and the dissolved gases of the water have been previously reported (Talma et al., 1984; Heaton et al., 1986).

\section{Study area}

The artesian Uitenhage Aquifer is located near the town of Uitenhage along the SE coast of Cape Province, South Africa (Fig. 2). Low salinity groundwater $(<300 \mathrm{mg} / 1 \mathrm{TDS})$ is contained within the
Ordovician quartzite of the Table Mountain Group. Water flows through this very dense rock, having no primary porosity, via a network of fractures from the outcrop region in the west, toward the Indian Ocean (Fig. 3). The flow path parallels the E-W-trending fold axis and faults. East of the recharge area, the quartzites are unconformably overlain by sandstones and shales of the Upper Jurassic-Lower Cretaceous Uitenhage Group. The steeply dipping contact between the Table Mountain Group and the shales of the Bokkeveld Group establishes the aquifer's northern boundary.

\section{Sampling and analytical methods}

Groundwater was collected from the quartzite outcrop, from springs at the edge of the outcrop, and from wells in the confined portions of the aquifer (Figs. 2 and 3). At each site, 20-1 samples for uranium analysis were collected in plastic containers. The samples were acidified to $\mathrm{pH}=$ 1, and a ${ }^{232} \mathrm{U}$ spike and $\mathrm{Fe}^{3+}$ carrier were added. In the laboratory, the $\mathrm{U}$ isotopes were measured by established procedures, using isotope dilution, ion-exchange and alpha-spectrometry (Ivanovich and Harmon, 1992). Water was also collected in special gas flasks (Heaton and Vogel, 1981) for the dissolved oxygen and for radon-radium. The dissolved oxygen was extracted from the flasks and measured by mass spectrometry. ${ }^{222} \mathrm{Rn}$ was stripped from the water and measured in a gas proportional counter. After a storage period of over a month, the $\mathrm{Rn}$ gas was once again stripped and re-measured to yield the activity of the supporting Ra parent.

\section{Results}

All analytical data, as well as previously reported radiocarbon data, are presented in Table 1 . The age of the groundwater increases uniformly with distance from the recharge region (Fig. 4). The measurement of the dissolved oxygen reveals that a reducing front is present down dip in the confined portions of the aquifer (Fig. 5). The measurement of ${ }^{238} U$ concentrations demonstrates the dependency of $U$ solubility on the oxidizing conditions of the water. As water 


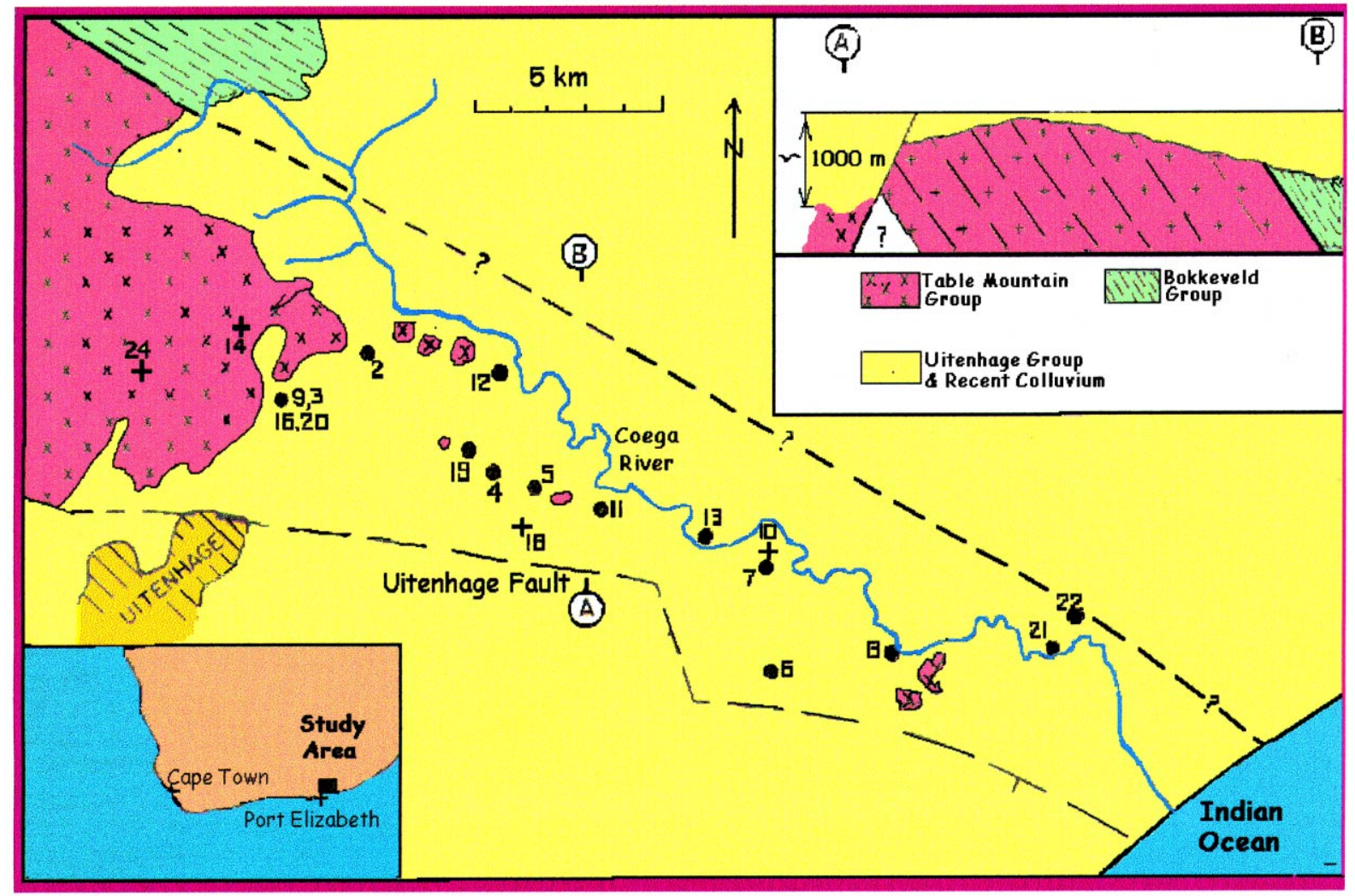

Fig. 2. Sample location and geological map of the Uitenhage Aquifer.

flows into the oxygen-depleted front, the uranium is very effectively removed from the water (Fig. 6). Concomitantly, there is a general increase in the
${ }^{234} \mathrm{U} /{ }^{238} \mathrm{U}$ activity ratio in the water that parallels the decrease in $U$ concentration (Fig. 7). This increase cannot be the result of a process of selective leaching

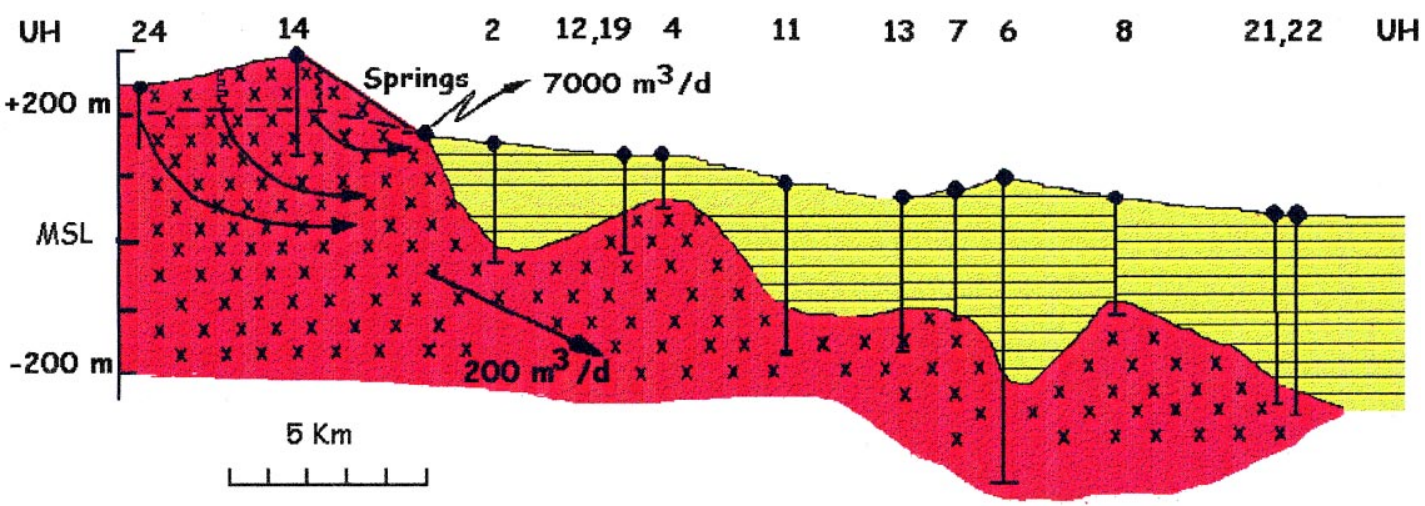

Uitenhage Group (aquiclude)

$x \times \times x$ Table Mountain Group (aquifer)

Fig. 3. W-E hydrological cross-section of the Uitenhage Aquifer. 
Table 1

Uranium-series isotopes, oxygen and age data for the main hydrologic sequence of the Uitenhage Aquifer (UH)

\begin{tabular}{|c|c|c|c|c|c|c|}
\hline Sample no. UH & $\begin{array}{l}\mathrm{U} \\
(\mu \mathrm{g} / \mathrm{l})\end{array}$ & $\begin{array}{l}{ }^{234} \mathrm{U} /{ }^{238} \mathrm{U} \text {-activity } \\
\text { ratio }\end{array}$ & $\begin{array}{l}{ }^{226} \mathrm{Ra} \\
(\mathrm{dpm} / \mathrm{kg})\end{array}$ & $\begin{array}{l}{ }^{222} \mathrm{Rn} \\
(\mathrm{dpm} / \mathrm{kg})\end{array}$ & $\begin{array}{l}\mathrm{O}_{2} \\
\left(\mathrm{ml}_{\mathrm{n}} / \mathrm{kg}\right)\end{array}$ & ${ }^{14} \mathrm{C}$ age \\
\hline $4 b$ & $0.056 \pm 0.006$ & $2.08 \pm 0.18$ & $10.8 \pm 0.4$ & $3,290 \pm 120$ & 0.08 & 8,570 \\
\hline $6 b$ & & & $7.9 \pm 0.1$ & $1,980 \pm 20$ & 0.18 & 22,900 \\
\hline $7 b$ & $0.017 \pm 0.003$ & $2.75 \pm 0.41$ & $14.7 \pm 0.1$ & $3,650 \pm 120$ & 0.04 & 21,200 \\
\hline $8 \mathrm{a}$ & & & & & & 23,400 \\
\hline $8 b$ & $0.013 \pm 0.002$ & $2.74 \pm 0.42$ & $6.8 \pm 0.4$ & $3,160 \pm 140$ & 0.17 & 16,000 \\
\hline $8 \mathrm{c}$ & & & $6.7 \pm 0.2$ & $2,680 \pm 30$ & 0.16 & 21,700 \\
\hline $9 b$ & $0.23 \pm 0.020$ & $1.41 \pm 0.11$ & $11.7 \pm 0.2$ & $45,400 \pm 800$ & 4.66 & 1,560 \\
\hline 11 & $0.018 \pm 0.004$ & $2.31 \pm 0.23$ & & & 0.73 & 7,860 \\
\hline 12 & $0.011 \pm 0.003$ & $2.20 \pm 0.23$ & $8.1 \pm 0.2$ & $180 \pm 70$ & 0.06 & 4,920 \\
\hline $13 \mathrm{a}$ & $0.015 \pm 0.002$ & $1.97 \pm 0.27$ & $9.5 \pm 0.2$ & $3,130 \pm 180$ & 0.53 & 18,200 \\
\hline $13 b$ & & & $10.2 \pm 0.2$ & $3,920 \pm 10$ & 0.16 & \\
\hline 14 & $0.097 \pm 0.008$ & $1.96 \pm 0.19$ & $9.0 \pm 0.2$ & $66,000 \pm 600$ & 3.31 & 350 \\
\hline 16 & $0.17 \pm 0.01$ & $1.30 \pm 0.09$ & $4.4 \pm 0.1$ & $13,400 \pm 80$ & $4.09,{ }^{\mathrm{a}}$ & 1,840 \\
\hline 19 & $0.0058 \pm 0.0025$ & $6.90 \pm 2.00$ & $18.6 \pm 0.02$ & $2,510 \pm 20$ & 0.20 & 4,770 \\
\hline 20 & $0.21 \pm 0.01$ & $1.42 \pm 0.08$ & $9.4 \pm 0.2$ & $77,800 \pm 200$ & $3.98,^{\mathrm{a}}$ & 1,350 \\
\hline 21 & & & $7.5 \pm 0.2$ & $3,410 \pm 20$ & 0.18 & 28,000 \\
\hline 22 & & & $5.3 \pm 0.2$ & $1,710 \pm 10$ & 0.14 & 27,800 \\
\hline 24 & $1.00 \pm 0.03$ & $0.91 \pm 0.04$ & $2.2 \pm 0.1$ & $84,400 \pm 200$ & 0.89 & 0 \\
\hline
\end{tabular}

${ }^{\text {a }}$ Sampling conditions suggest $\mathrm{O}_{2}$ analyses possibly unreliable.

of the ${ }^{234} \mathrm{U}$ nuclide (Rosholt et al., 1964), since elemental $\mathrm{U}$ is being removed from the water. Rather, we are witnessing the importance of the alpha-recoil effect. In the decay of ${ }^{238} \mathrm{U}$, the recoiling nucleus (now ${ }^{234} \mathrm{Th}$ ) is physically ejected from the precipi-

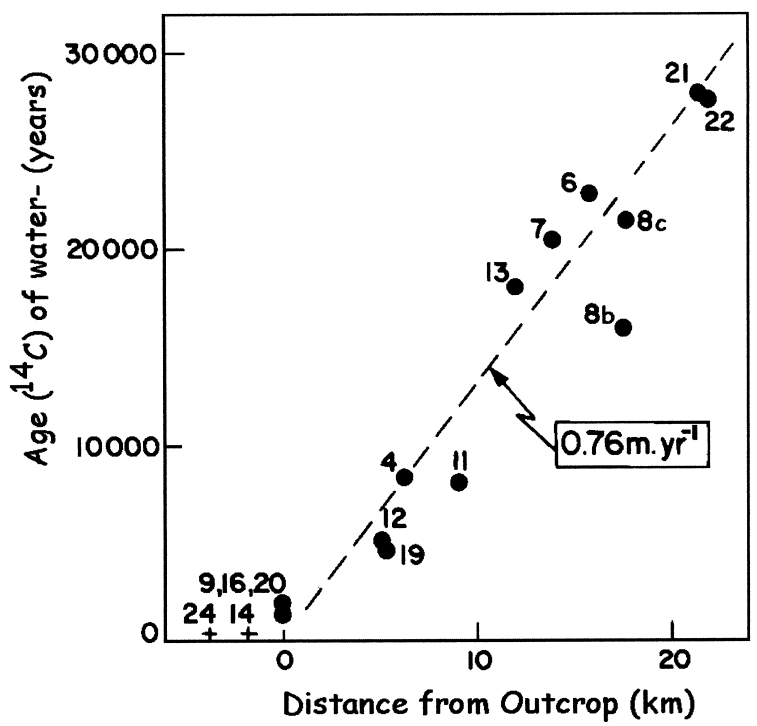

Fig. 4. The age and the rate of flow of groundwater in the Uitenhage Aquifer. tated $\mathrm{U}$ into the water, where in short order it decays to ${ }^{234} \mathrm{~Pa}$ and then to ${ }^{234} \mathrm{U}$ (Fig. 1). The ${ }^{234} \mathrm{U} /{ }^{238} \mathrm{U}$ activity ratio will be highest where removal of $U$ has been most effective (lowest ${ }^{238} \mathrm{U}$ activity in the water). This is the site where there is the largest ${ }^{238} \mathrm{U}$ accumulation on the surface of the solid phase. This in turn generates the largest transfer of new ${ }^{234} \mathrm{U}$ to the water by alpha-recoil processes.

The Uitenhage Aquifer water is characterized by a U-series nuclide activity in the order $\mathrm{Rn}>\mathrm{Ra}>$ $\mathrm{U}$ (Table 1). There is no significant variation in the generalized $\mathrm{Ra}$ activity throughout the 28,000-year history of the aquifer (Fig. 8).

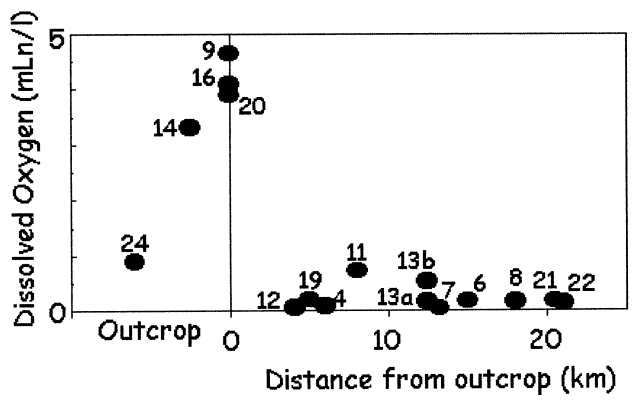

Fig. 5. Distribution of dissolved oxygen in the Uitenhage Aquifer. 


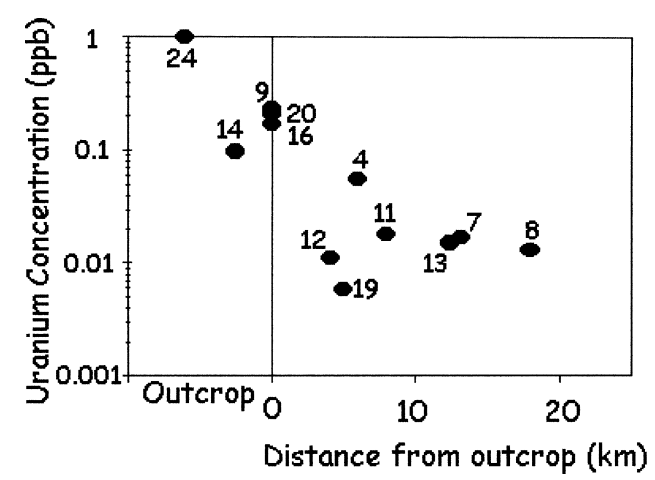

Fig. 6. Concentration of dissolved uranium in the groundwater.

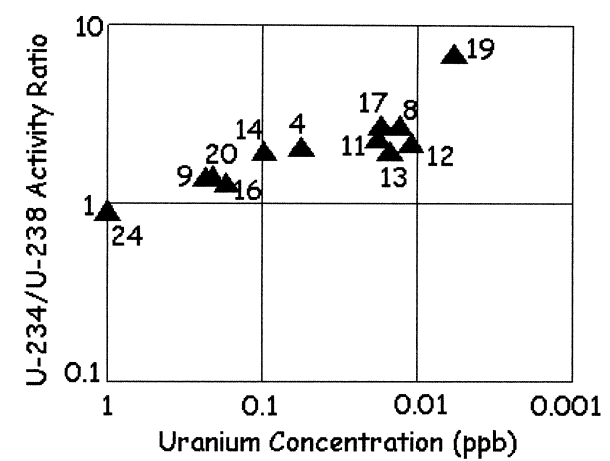

Fig. 7. Increasing ${ }^{234} \mathrm{U} /{ }^{238} \mathrm{U}$-activity ratios in the groundwater corresponds to decreasing uranium concentrations.

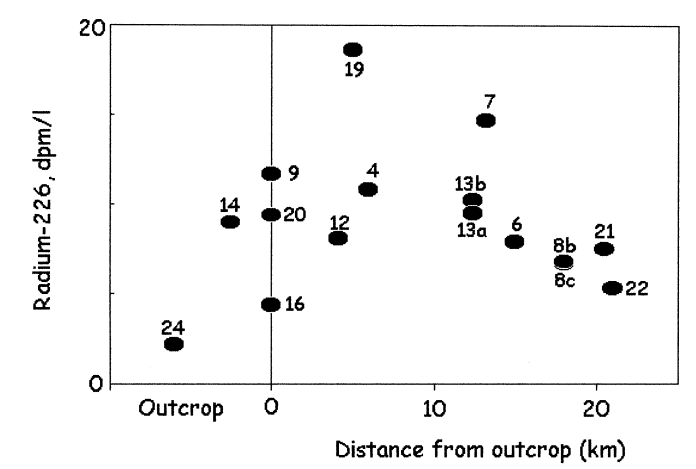

Fig. 8. Activity of soluble radium (relatively unchanging) in the groundwater.

\section{Discussion}

It should be borne in mind that in the Uitenhage Aquifer the water is transmitted along a series of fissures within impermeable quartzite. Though the age relationship illustrates an idealized flow path, it is possible that local environmental conditions within the parallel sets of fractures may have been somewhat variable in their effectiveness in precipitating uranium. Yet it can be seen that the present reducing barrier lies at, or up dip, from the $\sim 5000$ year radiocarbon contour (samples 12 and 19).

The age of the water in the confined portions of the aquifer is large compared to the half-lives of $\mathrm{Ra}$ and $\mathrm{Rn}$. Excess (unsupported) $\mathrm{Rn}$ and $\mathrm{Ra}$, that may have been introduced with the replenishment water, would have decayed away over the time that has elapsed. Radium present in the water thus differs from the $U$ which entered solution primarily at the site of recharge. The Ra activity, which is greater than its parent in the water, must be the result of a steady-state condition that exists, which balances input from the rock against radioactive decay in the water. This is achieved within the confines of the aquifer. Therefore, it appears most probable that the measured $\mathrm{Ra}$ has been injected via alpha-recoil from its immediate ${ }^{230} \mathrm{Th}$ parent. Part of the ${ }^{230} \mathrm{Th}$ is deposited as a continuous rain by the ubiquitous soluble U. The ${ }^{230} \mathrm{Th}$ precipitated in this manner on rock surfaces generates only a small portion of the ${ }^{226} \mathrm{Ra}$ excess. ${ }^{230} \mathrm{Th}$ will also be produced over time, from $U$ that has precipitated on the rock at the site of the redox barrier. Ingrowth of the shorter-lived ${ }^{226} \mathrm{Ra}$ and its ${ }^{222} \mathrm{Rn}$ daughter will follow suit. The ${ }^{226} \mathrm{Ra}$ in solution supports only a negligible fraction of the ${ }^{222} \mathrm{Rn}$ in solution. Therefore, the $\mathrm{Rn}$ that is measured has to be generated by $\mathrm{Ra}$ that must reside on the walls of the aquifer. The water flows at an average rate of $0.8 \mathrm{~m} / \mathrm{yr}$ (Fig. 4). The ${ }^{222} \mathrm{Rn}$, with a half-life of under four days, must mirror the relative concentration of its ${ }^{226} \mathrm{Ra}$ parent in the immediate vicinity of the sampling site. In the absence of appreciable dissolved $\mathrm{Ra}$, the $\mathrm{Rn}$ in the water ultimately reflects the abundance of its ${ }^{230} \mathrm{Th}$ grandparent on the rock surface. The ${ }^{222} \mathrm{Rn}$ excess (Fig. 9) does not parallel that of its parent ${ }^{226} \mathrm{Ra}$, except in the portions of the aquifer down dip from the present reducing barrier. There is a much greater excess of $\mathrm{Rn}$ in the young waters. This large excess appears to decrease exponentially with age until a steady-state value is achieved down dip of the present reducing barrier. The 'apparent' logarithmic decrease in $\mathrm{Rn}$ actually represents a build-up of ${ }^{230} \mathrm{Th}$ (and subsequently ${ }^{226} \mathrm{Ra}$ ), which 


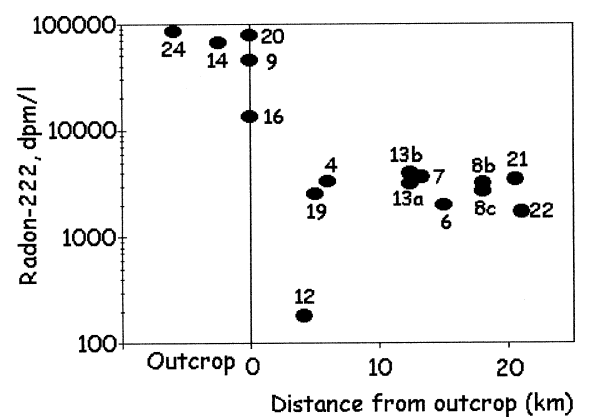

Fig. 9. Decrease in soluble radon down dip from the recharge region.

was produced from the decay of $U$ that precipitated on the rock surface when it entered the zone of reduction. As the front of the reducing barrier moved downstream in response to oxygen penetration, it left behind a trail of precipitated U-derived ${ }^{230} \mathrm{Th}$. Since the $U$ is largely immobile, the $\mathrm{Rn}$ activity in the water can be taken as being a proxy of the activity of ${ }^{230} \mathrm{Th}$. The oldest position of the reducing barrier will have the greatest amount of ingrown ${ }^{230} \mathrm{Th}$ (taking the reasonable assumption of a fairly constant $U$ concentration in the recharge water over time). Assuming that the reducing barrier was perpendicular to the flow direction, as is the case in the roll fronts of sandstone-type ores, then the $\mathrm{Rn}$ activity in the water reveals the direction that the reducing barrier has taken. At the present site of the reducing zone in the Uitenhage Aquifer, the $\mathrm{Rn}$ activity is significantly lower than in the recharge. Thus the front of the present reducing barrier has migrated down dip. The difference in Rn activity between these two sites is equivalent to an amount that can be generated by ${ }^{230} \mathrm{Th}$ build-up over a period of between 3 and 4 of its half-lives. The half-life is approximately 75,000 years. It is thereby suggested that the present front of oxygen depletion is of the order of $10^{5}$ years younger than the oldest remnant of the previous, upstream reducing front.

Several types of reducing barrier may potentially be created within an aquifer. By evaluating the $\mathrm{Rn}-\mathrm{U}$ profiles along the direction of groundwater flow, the type of reducing barrier may be resolved. Several basic combinations of activity profiles of $\mathrm{Rn}$ and $\mathrm{U}$ in water (along with a consideration of the Th on the rock surface), that can be related to a specific type of reducing barrier, can be illustrated (Fig. 10).

\subsection{Type 1}

A stable barrier is one that has been established at a specific site for a time that is long compared to the half-life of ${ }^{230} \mathrm{Th}$. The ${ }^{230} \mathrm{Th}$ that builds up supported by its parent $\mathrm{U}$ on the aquifer wall, is greater than the ${ }^{230} \mathrm{Th}$ that is ubiquitously and continuously 'raining' down on the aquifer walls from the soluble $U$ in the water column. A sharp Rn spike characterizes the profile that marks the position of the reducing barrier.

\subsection{Type 2}

Narrow band of deposition. (A) A very slowly migrating barrier (relative to the half-life of ${ }^{230} \mathrm{Th}$ ) builds up a relatively thick and abundant source of supported ${ }^{230} \mathrm{Th}$ along the path of migration. High $\mathrm{Rn}$ activities are encountered that drop off abruptly to uniformly lower activities down dip of the front of the reducing barrier. The low Rn values parallel the low soluble $\mathrm{U}$ activities beyond the barrier's front. (B) A more rapidly migrating barrier leaves behind a trail of decreasing amounts of ${ }^{230} \mathrm{Th}$, until the present site of the reducing front is reached. The Rn activity mirrors the ${ }^{230} \mathrm{Th}$ build-up, while the $\mathrm{U}$ concentration in the water becomes sharply reduced at a point. This model appears to best suit the analytical data obtained from the Uitenhage Aquifer.

\subsection{Type 3}

Broad band of deposition. (A) Uranium is precipitated exponentially along the course of flow from the recharge region. Redox conditions in such a case would not facilitate the development of a discrete barrier restricted to a well defined region. (B) Uranium is linearly precipitated along the aquiferal course. In this case, a specific quantity of $U$ is precipitated for each volume of aquiferal rock encountered along the flow path. This will result in uniform ${ }^{230} \mathrm{Th}$ activity and Rn activity up dip of the point to where almost all of the soluble $U$ becomes exhausted.

\section{Conclusions}

It appears unlikely that an ore could be found within the Uitenhage Aquifer, despite the long time 


\section{Stable Barrier}

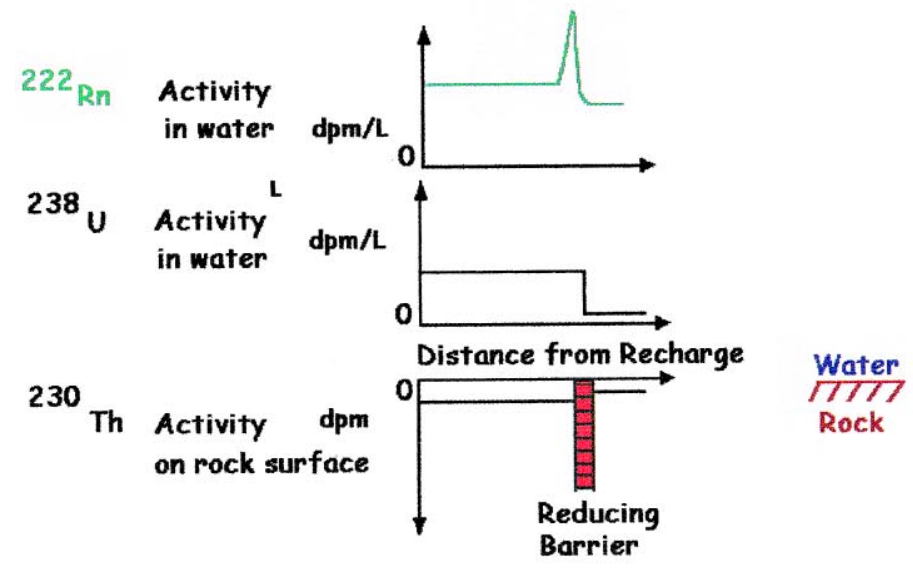

2. Narrow Zone of Deposition

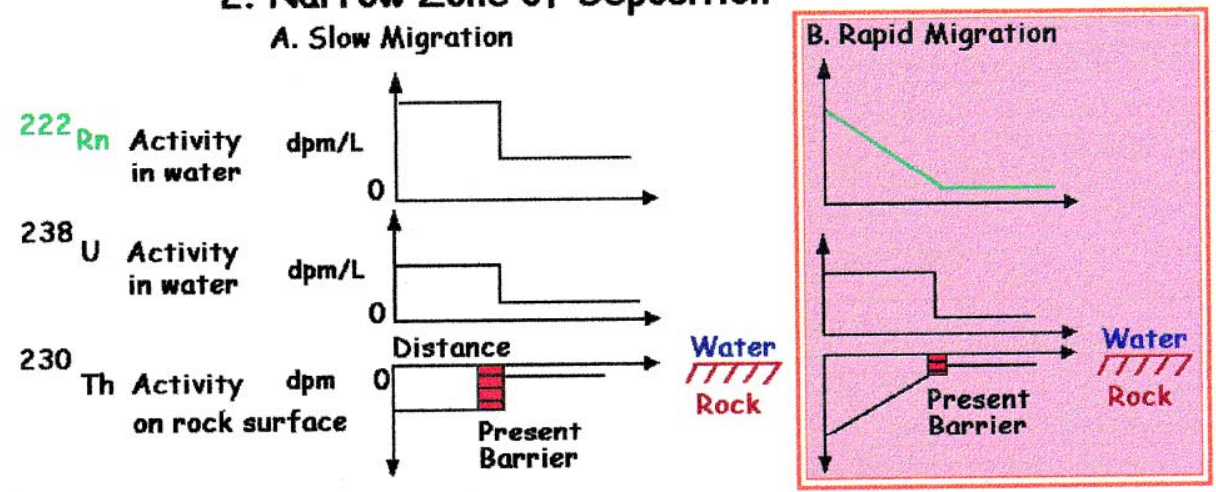

\section{Broad Band of Deposition}

\section{A. Exponential Precipitation of Uranium}

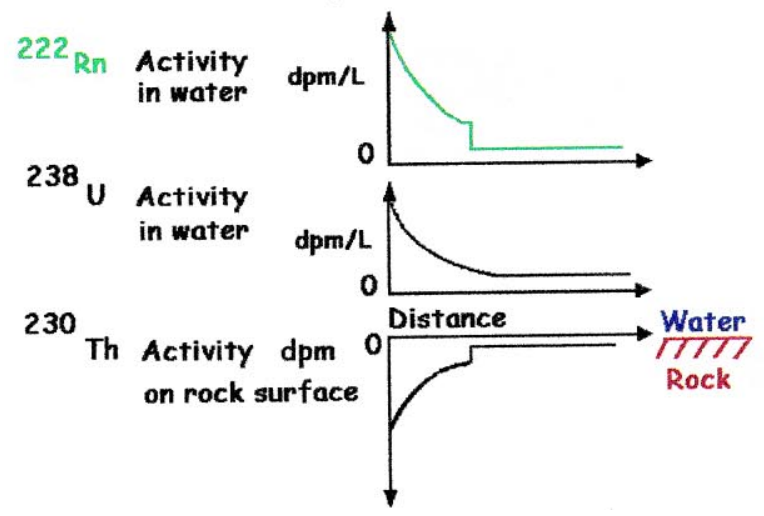

B. Linear Rate of Removal of Uranium

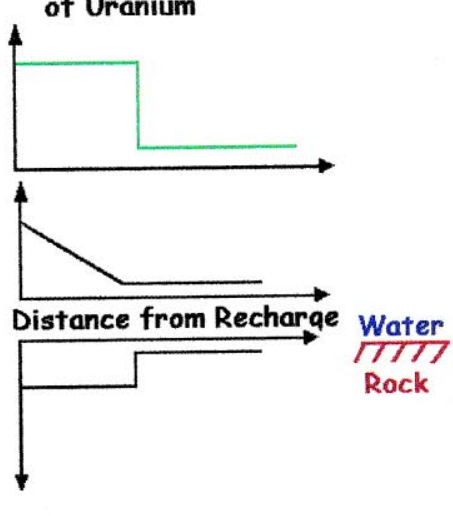

Fig. 10. Radon-uranium-activity models for various types of potential reducing barriers. 
of uranium accumulation. This is because both the absolute amount of uranium in the water is not great, and more important, the $U$ that has precipitated has not accumulated along a fixed front. This front has migrated steadily over time. Thus, the mass of $U$ has been smeared out over kilometers, at low concentrations, along a stretch of the aquifer. Though economic uranium concentrations were not encountered in this study, the investigation serves to demonstrate the importance of investigating not only the present redox conditions (as it pertains to $\mathrm{U}$ deposition), but the need to understand the past position(s) of the uranium precipitation front. These are revealed by a combined study of the soluble uranium, radium and radon, combined with a knowledge of the rate of groundwater flow.

\section{References}

Heaton, T.H.E., Vogel, J.C., 1981. 'Excess-air' in groundwater. J. Hydrol. 50, 201-206.

Heaton, T.H.E., Talma, A.S., Vogel, J.C., 1986. Dissolved gas paleotemperatures and ${ }^{18} \mathrm{O}$ variations derived from groundwater near Uitenhage, South Africa. Quat. Res. 25, 79-88.

Ivanovich, M., Harmon, R.S. (Eds.), 1992. Uranium-series Disequilibrium: Applications to Earth, Marine, and Environmental Sciences, 2nd Edn. Clarendon Press, Oxford.

Kigoshi, K., 1971. Alpha-recoil thorium: dissolution into water and the uranium-234/uranium-238 disequilibrium in nature. Science 173, 47-48.

Kronfeld, J., 1974. Uranium deposition and Th-234 alpha-recoil: an explanation for extreme U-234/U-238 fractionation within the Trinity aquifer. Earth Planet. Sci. Lett. 21, 327-330.

Rosholt, J.N., Harshman, E.N., Shields, W.R., Garner, E.L., 1964. Isotopic fractionation of uranium related to roll features in sandstone Shirley Basin, Wyoming. Econ. Geol. 59, 570585.

Talma, A.S., Vogel, J.C., Heaton, T.H.E., 1984. The geochemistry of the Uitenhage artesian aquifer: carbonate solution in a closed system. In: Isotope Hydrology 1983. Int. Atom. Energy Agency, Vienna, pp. 481-487. 